\title{
$\mathbf{J}|\mathbf{A}| \mathbf{C} \mid \mathbf{S}$ \\ COMMUNICATIONS
}

Published on Web 12/11/2001

\section{Laterally Stabilized Complexes of DNA with Linear Reducible Polycations: Strategy for Triggered Intracellular Activation of DNA Delivery Vectors}

\author{
David Oupický, ${ }^{*}$ Alan L. Parker, and Leonard W. Seymour \\ CRC Institute for Cancer Studies, University of Birmingham, Birmingham B15 2TT, United Kingdom
}

Received June 18, 2001

Polyelectrolyte complexes of DNA represent an important alternative to viruses in the development of efficient vectors for gene therapy. Our research focuses on polycation-based vectors, surface stabilized with hydrophilic polymers to decrease nonspecific interactions with biological components and ensure suitability for intravenous delivery. We have developed a method to surfacemodify the polycation/DNA vectors using multivalent hydrophilic copolymers of $\mathrm{N}$-(2-hydroxypropyl) methacrylamide with methacryloylglycylglycine 4-nitrophenyl ester (PHPMA). In contrast to coating with monovalent polymers, the multivalent coating introduces lateral stability into the complexes - a factor that promotes extended circulation in the bloodstream. This is a prerequisite for targeting disseminated disease targets (e.g. metastatic cancers). ${ }^{1}$ The versatile nature of this vector allows receptor-mediated targeting of genes to selected cells and manipulation of intracellular trafficking. The vector is stable enough to allow efficient in vivo delivery and prevent DNA degradation, however relatively low levels of gene expression suggest that the DNA is not available for transcription due to the retention of the polymer coating, restricting enzymatic access, and transcription efficiency. ${ }^{2}$ This indicates that poor release of DNA from this vector can be an important limiting step and highlights the need for a specific intracellular activation mechanism.

Strategies of specific intracellular activation of drug and gene delivery vectors already have been established for several types of carriers. ${ }^{3-7}$ Here we describe an innovative approach to the design of the PHPMA-stabilized vectors, which makes use of the significant intracellular reducing capacity ${ }^{8,9}$ to reverse the lateral stabilization introduced by surface coating with PHPMA, facilitating release of the delivered DNA. The design of the vector can thus satisfy the contradictory requirements for high stability in the extracellular environment and easy intracellular availability of DNA. This is achieved by a unique combination of steric and reversible lateral stabilization by PHPMA of vectors based on plasmid DNA complexed with a reducible linear polycation. Intracellular reductive degradation of the polycation to lower molecular weight species removes the lateral stabilizing effect of the PHPMA coating, enabling efficient transcription of the plasmid DNA (Scheme 1).

Oxidative polycondensation of Cys(Lys) ${ }_{10}$ Cys peptide (prepared by standard Fmoc/tBoc chemistry) with dimethyl sulfoxide ${ }^{10}$ provided the reductively cleavable linear polycations (RPC) by oxidation of the terminal cysteinyl thiol groups (Scheme 1). The reaction kinetic shows typical features of step-growth polymerization, i.e., molecular weight of the resulting polymer increases with time, and high conversion degrees of functional thiol groups must be reached to obtain high molecular weight products (Figure 1). ${ }^{11}$ Molecular weight of the RPC can be easily controlled by introducing compounds containing single thiol functionality into the polycon-

* To whom correspondence should be addressed.
Scheme 1. Reversible Lateral Stabilization of DNA Complexes

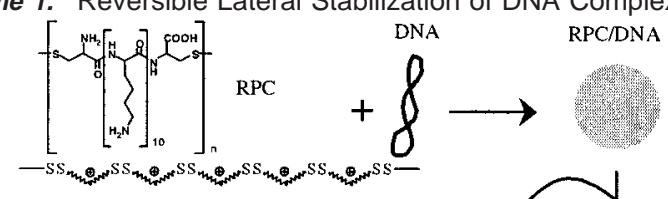
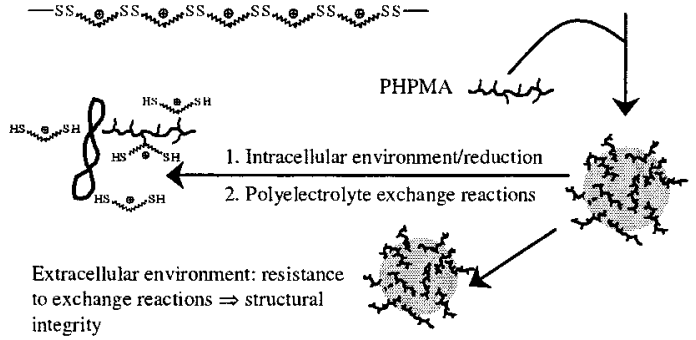

densation reaction. Here, RPC with molecular weight $\left(M_{\mathrm{w}}\right) 187000$ $\left(\mathrm{RPC}(187 \mathrm{k}), M_{\mathrm{w}} / M_{\mathrm{n}}=1.9\right)$ was prepared by polycondensation in the absence of any molecular weight regulator and RPC with molecular weight 45000 (RPC(45k), $M_{\mathrm{w}} / M_{\mathrm{n}}=2.1$ ) was synthesized in the presence of $8 \mathrm{~mol} \%$ of 2 -aminoethanethiol. ${ }^{12}$ This method for synthesis of reductively degradable polycations enables simple linkage of thiol-containing functional molecules (fluorescent labels, bioactive peptides) during polymerization, at the termini of the macromolecule. It also allows better control of polymerization, polycation properties, and purity than alternative template polycondensations ${ }^{13,14}$ or random cross-linking strategies. ${ }^{15}$

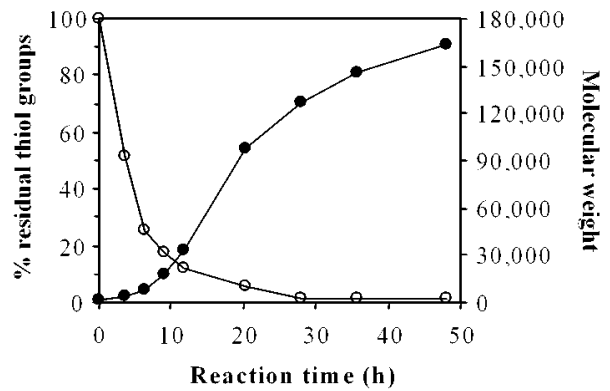

Figure 1. Time course of oxidative polycondensation of Cys(Lys) ${ }_{10}$ Cys. ${ }^{11}$ (Molecular weight $[\bullet]$ and \% residual thiol groups [O] vs time.)

DNA complexes of both RPC and control poly-L-lysines $\left(M_{\mathrm{w}}\right.$ 29000 and 205 000) (PLL(29k); PLL(205k)) were prepared by addition of the polycation to a solution of pGL3-con plasmid (20 $\mu \mathrm{g} / \mathrm{mL}$ ) in $10 \mathrm{mM}$ HEPES $\mathrm{pH} 7.4$ (polycation amines-to-DNA phosphates $\mathrm{N}: \mathrm{P}$ ratio $=2$ ) and coated with $0.2 \mathrm{mg} / \mathrm{mL}$ of PHPMA (molecular weight $55000 ; 8 \mathrm{~mol} \%$ of reactive 4-nitrophenoxy groups) in $40 \mathrm{mM}$ HEPES pH 7.8 overnight. Hydrodynamic size of complexes was analyzed by dynamic light scattering and the changes caused by addition of $\mathrm{NaCl}$ were measured. As expected, both RPCs bound to plasmid DNA, forming complexes of similar 


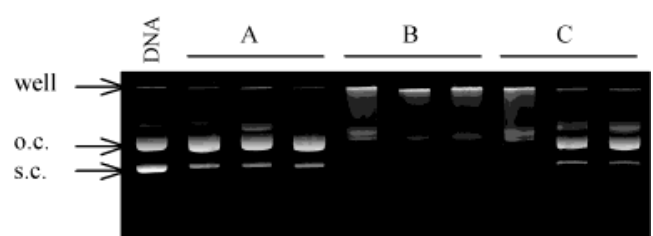

Figure 2. Lateral stabilization of polycation/DNA complexes by surface coating with PHPMA. Resistance to polyelectrolyte exchange reactions with $2 \mathrm{mg} / \mathrm{mL}$ poly-L-aspartic acid (PAA). Group A: polycation/DNA + PAA. B: PHPMA-polycation/DNA + PAA. C: PHPMA-polycation/DNA + PAA $+2.5 \mathrm{mM}$ DTT (from left to right in each group complexes based on PLL(29k); RPC(45k) and RPC (187k)) (s.c. = supercoiled, o.c. $=$ open circular form of plasmid DNA)

Table 1. Transfection Activity of DNA Complexes Laterally Stabilized by Surface Coating with PHPMA ${ }^{24}$

\begin{tabular}{lcc}
\hline & \multicolumn{2}{c}{ transfection efficiency (RLU/mg protein) } \\
\cline { 2 - 3 } complex composition & PHPMA-coated & $\begin{array}{c}\text { PHPMA-coated and } \\
\text { bFGF targeted }\end{array}$ \\
\hline RPC(187k)/DNA & $(2.24 \pm 0.20) \times 10^{6}$ & $(1.12 \pm 0.15) \times 10^{7}$ \\
PLL(205k)/DNA & $(9.53 \pm 6.70) \times 10^{4}$ & $(1.73 \pm 1.69) \times 10^{5}$ \\
\hline
\end{tabular}

sizes and $\zeta$-potentials $(30-35 \mathrm{mV})$ as their PLL equivalents. During PHPMA coating of complexes the hydrodynamic diameter increased from 70 to $86 \mathrm{~nm}$ in the case of RPC(187k) and from 65 to $80 \mathrm{~nm}$ (RPC $(45 k))$. Similar values were obtained for both control PLLbased complexes. ${ }^{16}$ PHPMA coating also suppressed the high positive $\zeta$ potential of simple polycation/DNA complexes and produced a negative charge $(\sim-10 \mathrm{mV}) .{ }^{17}$ Surface modification with PHPMA also led to steric stabilization of DNA complexes, shown by suppression of salt-induced aggregation compared to nonmodified complexes.

Lateral stabilization by surface cross-linking of complexes with multivalent PHPMA can be assessed by studying polyelectrolyte exchange reactions. These reactions play an essential role in the whole process of DNA delivery. ${ }^{18}$ While exchange reactions should be minimal during the extracellular (stabilized) delivery phase of the vector, these reactions may mediate release of the DNA inside cells following intracellular reductive activation. ${ }^{18,19}$ Stability of the PHPMA coated complexes was assessed by incubation with PAA $(2 \mathrm{mg} / \mathrm{mL})$ overnight $\pm 2.5 \mathrm{mM}$ DTT, with analysis by agarose gel electrophoresis. DNA was released easily from all nonmodified complexes, however surface coating with PHPMA suppressed the PAA exchange reaction for all complexes (i.e. both RPC and control PLL(29k)) in the absence of DTT (Figure 2). ${ }^{20}$ Treatment of coated complexes with DTT enabled only complexes containing RPC to release free DNA upon incubation with PAA, validating the concept of reductive activation.

To verify the biological usefulness of the reductive trigger mechanism we compared transfection activity of PHPMA-coated vectors based on RPC(187k) and PLL(205k) in human retinoblast 911 cells (Table 1). ${ }^{21}$ Transgene expression was low for PHPMA coated PLL(205k)/DNA complexes, presumably due to low cellular uptake and high stability. To increase cell entry, basic fibroblast growth factor (bFGF) was covalently linked to the surface of complexes as a targeting agent. ${ }^{22}$ Targeting with bFGF increased transfection activity of both reducible and nonreducible vectors, although transgene expression was particularly high for vectors based on reducible $\mathrm{RPC}(187 \mathrm{k}){ }^{23}$ This supports the proposed mechanism of intracellular activation of the vector, authenticating the concept of reversible lateral stabilization by surface coating with PHPMA.

Acknowledgment. We thank Libuše Oupická for technical assistance, BBSRC and CRC for financial support, Karel Ulbrich for the HPMA copolymer, and Selective Genetics for the kind gift of bFGF.

\section{References}

(1) Oupicky, D.; Ogris, M.; Howard, K. A.; Dash, P. R.; Seymour, L. W Mol. Ther. in press.

(2) Fisher, K. D.; Ulbrich, K.; Subr, V.; Ward, C. M.; Mautner, V.; Blakey, D.; Seymour, L. W. Gene Ther. 2000, 7, 1337-1343.

(3) Rui, Y. J.; Wang, S.; Low, P. S.; Thompson, D. H. J. Am. Chem. Soc. 1998, 120, 11213-11218.

(4) Tang, F. X.; Hughes, J. A. Bioconjug. Chem. 1999, 10, 791-796.

(5) Kirpotin, D.; Hong, K. L.; Mullah, N.; Papahadjopoulos, D.; Zalipsky, S. FEBS Lett. 1996, 388, 115-118

(6) Zalipsky, S.; Qazen, M.; Walker, J. A.; Mullah, N.; Quinn, Y. P.; Huang, S. K. Bioconjug. Chem. 1999, 10, 703-707.

(7) Kakizawa, Y.; Harada, A.; Kataoka, K. J. Am. Chem. Soc. 1999, 121, $11247-11248$

(8) Bellomo, G.; Vairetti, M.; Stivala, L.; Mirabelli, F.; Richelmi, P.; Orrenius, S. Proc. Natl. Acad. Sci. U.S.A. 1992, 89, 4412-4416.

(9) Meister, A. Pharm. Therapeutics 1991, 51, 155-194.

(10) Tam, J. P.; Wu, C. R.; Liu, W.; Zhang, J. W. J. Am. Chem. Soc. 1991, $113,6657-6662$.

(11) The polycondensations were performed at $30 \mathrm{mM}$ Cys(Lys $)_{10}$ Cys concentration in phosphate-buffered saline containing 30 vol \% DMSO. The conversion of the functional thiol groups was followed by the quantification with 5,5'-dithiobis(2-nitrobenzoic acid) (Ellman's reagent) and molecular weights (weight averages) of resulting RPC at various time points were measured by size exclusion chromatography (SEC) using calibration with commercially available poly-L-lysines (PLL) with molecular weights in the range 3400-205000.

(12) Both RPC were purified from DMSO and cyclic byproducts using centrifugal ultrafilters with molecular weight cutoff 10000 . The concentrations of RPC were determined by 2,4,6-trinitrobenzenesulfonic acid using PLL calibration. Degradability of both RPC to the initial was confirmed by SEC following reduction with $5 \mathrm{mM}$ dithiothreitol (DTT)

(13) McKenzie, D. L.; Kwok, K. Y.; Rice, K. G. J. Biol. Chem. 2000, 275, 9970-9977.

(14) Trubetskoy, V. S.; Budker, V. G.; Hanson, L. J.; Slattum, P. M.; Wolff, J. A.; Hagstrom, J. E. Nucleic Acids Res. 1998, 26, 4178-4185.

(15) Oupicky, D.; Carlisle, R. C.; Seymour, L. W. Gene Ther. 2001, 8, 713724

(16) For comparison, PLL (Mw 3,400) (used as a control for the starting peptide) forms colloidally very unstable complexes of over $300 \mathrm{~nm}$ in diameter with transfection activity 100-fold lower than that of the polymerized analogues RPC

(17) The negative charge of PHPMA-coated complexes arises from a partial hydrolysis of reactive 4-nitrophenoxy groups during the coating, yielding negatively charged carboxylate groups.

(18) Bronich, T. K.; Nguyen, H. K.; Eisenberg, A.; Kabanov, A. V. J. Am Chem. Soc. 2000, 122, 8339-8343.

(19) Schaffer, D. V.; Fidelman, N. A.; Dan, N.; Lauffenburger, D. A Biotechnol. Bioeng. 2000, 67, 598-606.

(20) In contrast, PHPMA coating complexes formed between DNA and low molecular weight PLL (MW 3400) did not increase resistance to polyelectrolyte exchange, i.e., had no effect on the lateral stability.

(21) The transfection activity of both RPC/DNA complexes (using pGL3-con plasmid) was similar to that of nondegradable PLL(29k).

(22) Addition of free bFGF to PHPMA-coated complexes had no effect on transfection activity.

(23) DOTAP achieved up to one log greater transgene expression than bFGFtargeted RPC complexes. However, DOTAP-mediated transfection is nonspecific, whereas bFGF-targeted RPC complexes act via specific membrane receptors. Transfection activity of bFGF-targeted vectors was inhibited when cells were preincubated with free bFGF $(50 \mu \mathrm{g} / \mathrm{mL})$.

(24) Polycation/DNA complexes $(\mathrm{N}: \mathrm{P}=2)$ were coated with $2 \mathrm{mg} / \mathrm{mL}$ of PHPMA for $2 \mathrm{~h}$ at $25^{\circ} \mathrm{C}$. Complexes used for targeting with bFGF were further reacted on ice overnight with $50 \mu \mathrm{g} / \mathrm{mL} \mathrm{bFGF}$. Any remaining reactive PHPMA groups were aminolyzed by addition of 2 -aminoethano $16 \mathrm{~h}$ later. Cells were incubated with the complexes at $37^{\circ} \mathrm{C}$ for $5 \mathrm{~h}$ with $10 \%$ foetal calf serum and $100 \mu \mathrm{M}$ chloroquine, and luciferase activity measured $48 \mathrm{~h}$ after transfection.

JA016440N 